\title{
Mesothelioma: time to take stock
}

\author{
Carol Tan Tom Treasure
}

J R Soc Med 2005;98:455-458

Mesothelioma is rapidly increasing in frequency, and the perception of this cancer is generally gloomy. It is widely considered to be resistant to chemotherapy and radiotherapy and to be an impossible operative target, so that very little can be done. Taken one at a time each of these beliefs can be challenged. In fact it is sensitive to both chemotherapy and radiotherapy. It is a challenging but not impossible surgical proposition. Combination therapies are the best hope of benefit.

We will describe the best management strategies we know and the evidence for them. 'Cure' would be a big claim. A more modest but realistic objective is to get the best symptom relief we can, for the longest possible time. Sometimes the sum of small things provides a worthwhile whole.

\section{EPIDEMIOLOGY}

In 1968, the first complete year of data after the British register of mesothelioma deaths was set up, there were just 153 registered deaths from mesothelioma. ${ }^{1}$ This number had risen to 1862 in 2002, and mesothelioma is now responsible for more deaths in the UK than either cervical cancer or malignant melanoma. ${ }^{2}$ The death rate is predicted to go on rising into the next decade, with a peak sometime between 2011 and 2015, at 1950 to 2450 deaths per year. Thereafter the number of deaths in the UK is expected to decline. $^{3}$

Most or nearly all UK mesothelioma deaths are due to asbestos exposure. The rise of mesothelioma deaths has been shown to follow the rise of asbestos imports in the $\mathrm{UK},{ }^{3,4}$ where exposure to asbestos continued widely until the 1980s (Figure 1). The latent period between first exposure to asbestos and the development and diagnosis of mesothelioma is seldom less than 15 years and can be as long as 60 years. Most deaths occur within one or two years of diagnosis. Particularly at risk are those who have previously worked in the shipbuilding and railway industries; however, because of the widespread use of asbestos in building sites, home improvements and many other uncontrolled construction work, a larger number of cases are amongst building trade craftsmen exposed

Department of Cardiothoracic Surgery, Guy's and St Thomas's, London SE1 9RT, UK

Correspondence to: Professor Tom Treasure

E-mail: Tom.Treasure@ukgateway.net

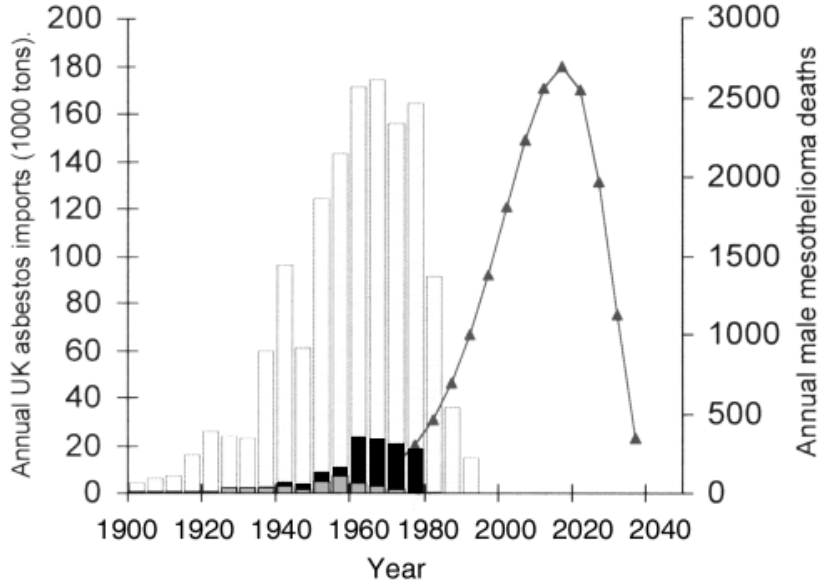

Figure 1 UK asbestos imports and predicted mesothelioma deaths in men born before 1953 (Ref. 2). $\square$ Chrysotile; $\square$ amosite; crocidolite; $\Delta$ predicted deaths

accidentally and often unknowingly. Victims include the wives and children of workers who brought asbestos dust home on their clothes. If current control measures are not adhered to, asbestos-removal workers are now potentially at high risk, as are workers who refurbish, repair or maintain buildings.

\section{ASBESTOS}

Asbestos (named from the Greek for inextinguishable or unquenchable) is the collective term given to a group of naturally occurring fibrous minerals mined since prehistory. The main types of asbestos are chrysotile (white asbestos) and the amphiboles, which include crocidolite (blue asbestos), amosite (brown asbestos), tremolite, actinolite and anthrophyllite. Chrysotile accounts for about 95\% of world production of asbestos.

Asbestos was used for the embalming of Egyptian Pharaohs in 4000-2000 BC and in more recent times was a constituent of lamp wicks. However, it was the properties of thermal stability and resistance, chemical resistance, high tensile strength, abrasion resistance, low electrical and thermal conductivity, low biodegradability and good sound absorption that led in the early 1870 s to the founding of large asbestos industries throughout the world. For the next century, asbestos was imported to the UK in large quantities $^{5}$ for use in construction, ship building and the manufacture of household appliances. Its extensive use in 
many commercial products including roofing materials, floor tiles, cement pipes and textiles has resulted in wide distribution of asbestos in the environment. Even the Wicked Witch of the West in the film The Wizard of $\mathrm{Oz}$ appeared on a broom made of asbestos.

Since it appeared to be such a valuable and versatile material, imports rose after the Second World War, and were at their highest from about 1955 to $1980 .^{5}$ Health concerns began to surface in the US and UK in the 1960s, when studies revealed hazards from even low-level exposure. Many years were to elapse, however, before the Asbestos Licensing Regulations (1983) and the Control of Asbestos at Work Regulations (1987) came into force in the UK. In 1992 the Asbestos Prohibition Regulation banned the importation and supply of asbestos. ${ }^{6}$

While we can at least be confident that the current epidemic will peak and decline in the coming decades in the UK, there is no such reassurance in certain newly industrialized and developing countries, where asbestos use continues to grow and there are no regulations to protect those who come into contact with it day to day. ${ }^{7}$ The health impact of this exposure is often dismissed in favour of the more immediate need for employment and economic growth. Thus some countries regard chrysotile as having an acceptable cost/risk ratio, on the argument that use of asbestos in the production of pipes will provide clean water to save hundreds and thousands of lives. ${ }^{8}$

\section{PATHOLOGY AND MANIFESTATIONS}

Mesothelioma is a slow-growing, primary cancer of the pleura, most commonly the parietal pleura. Arising from mesothelial cells it can also develop in the pericardium, peritoneum, tunica vaginalis testis and ovarian epithelium. While bloodborne metastasis to other organs is infrequent in the early phase, the tumour grows relentlessly into adjacent structures such as the heart, lungs and chest wall. Pain in the chest wall and breathlessness are common presenting symptoms and patients often visit the chest clinic for repeated aspiration or drainage of their pleural effusion before a diagnosis is finally made. This presents another problem: it has a particular propensity for growing down needle or drain tracks, producing subcutaneous nodules and eventually large masses of often painful tumour deposits.

Once the diagnosis is made, many if not all patients are already in advanced stages of the disease. It tends to progress quickly, sometimes with unremitting pain and usually with marked deterioration in pulmonary function and cachexia. The emphasis of care is usually on symptom relief. With a median survival of about twelve months from time of diagnosis, palliative treatments need to be given expeditiously and efficiently.

\section{SURGERY}

The traditional principles of oncological surgery are based on resection of the cancer within some anatomically defined organ boundaries, with good clearance margins, including the lymphatic drainage in continuity. Mesothelioma spreading along the pleura does not lend itself to that concept. The nature, extent, pattern of growth, and proximity to major organs have made typical cases of mesothelioma appear impossible to treat, let alone cure. Rising to the challenge Eric Butchart, whose name is inextricably linked with this operation, reported on 29 patients with mesothelioma in $1976 .{ }^{9}$ He had a leading role in the development of the most radical surgery, pleuropneumectomy, now usually referred to as extrapleural pneumonectomy. In this operation the lung is removed within the stripped parietal pleura. The pericardium and diaphragm are excised en bloc and replaced with prosthetic patches. This very radical surgery as a single modality has not been associated with any demonstrable increase in survival; ${ }^{10}$ however, its time may have returned as part of trimodality therapy where it is preceded by chemotherapy and followed by radiotherapy. ${ }^{11}$

\section{CHEMOTHERAPY}

Mesothelioma was at one time thought resistant to chemotherapy. In fact it is sensitive to a degree, but what does the patient gain? With single-agent chemotherapy alone the response rate has not been encouraging. ${ }^{12}$ In 2002, Berghman et al. ${ }^{13}$ reported in a systematic review that cisplatin was the most active single agent with an objective response rate of $23 \%$. In combination with doxorubicin, this produced the highest response rate $(28.5 \%, 95 \%$ confidence interval 21.3-35.7). Since then, Vogelzang et al. ${ }^{14}$ have reported a phase III randomized trial in 456 patients with unresectable mesothelioma in which cisplatin plus pemetrexed was compared with cisplatin alone. The results were in favour of combination therapy, with longer median time (12.1 months versus 9.3 months, $P=0.02$ ) and longer median time to progression (5.7 months versus 3.9 months, $P=0.001)$. The response rate of $41.3 \%$ (95\% CI 34.8-48.1) is the highest recorded in any chemotherapy trial so far.

In mesothelioma, response to chemotherapy is based on CT images before and after treatment. The diffuse nature of the disease makes quantification difficult and the variable volumes of pleural fluid can obscure the extent of disease. ${ }^{15}$ The statistics on response rates based on imaging may not parallel clinical effect, and the survival gains are modest. What is more important is whether there is benefit in terms of quality of life. Is it worth putting this group of patients through a chemotherapy regimen that may add life for the minority at the cost of impairing life quality for many? 


\section{RADIOTHERAPY}

Mesothelioma presents an impossible field for the radiotherapist. Radiotherapy has its best effect when a tumour can be encompassed in a small treated volume, without vulnerable organs in the field. The pleura has a very large surface area with the volume of disease widely dispersed. Within the three-dimensional space that the pleura encompasses lie the lung, heart, spinal cord, liver and kidney.

There is now clear evidence that mesothelioma responds to radiotherapy. We know this from the treatment of portsite seeding. A randomized trial in 40 patients showed that radiotherapy to previous sites of drain, aspiration or biopsy on the chest wall prevents growth of malignant nodules at these sites. ${ }^{16}$ Radiotherapy has also been shown to relieve chest wall pain. ${ }^{17}$

Radiotherapy alone has a very limited role but removal of the underlying lug and the bulk of the disease (extrapleural pneumonectomy) make the target volume treatable. In a phase II trial of surgical resection and adjuvant hemithoracic radiation, high-dose radiation has been shown to be feasible with acceptable toxicity and is likely to reduce local recurrence. ${ }^{18}$ Intensity-modulated radiotherapy is now also being proposed. ${ }^{19}$ So perhaps like surgery, where it has failed on its own, it may yet find a useful place in trimodality therapy.

\section{SURGERY: ITS CURRENT ROLE}

The surgeon in the multidisciplinary team has important diagnostic and palliative limitations. Both can be achieved during a quick, minimally invasive procedure (videoassisted thoracoscopy) under general anaesthesia, when an effusion may be drained, a pleural biopsy obtained and talc insufflated to induce pleural adhesions (pleurodesis). Prompt diagnosis and early effective palliation of breathlessness are well worth achieving and early surgical referral can be important in overall management.

Less clear is the role of surgical resection, whether in debulking of disease or the more radical extrapleural pneumonectomy. The mortality and morbidity for these procedures are much greater, and many reports of improved outcomes include the fittest patients with earlystage disease who are most likely to do well. ${ }^{18,20,21}$ Mischievous though it may seem to point it out, nearly all these claims follow this five point illogical sequence:

1 Statistically define the features predicting longer survival

2 Operate on those with favourable features

3 Do not operate on those with unfavourable features

4 Compare those we chose for surgery with those we did not operate on

5 Operated patients do better-QED.
To date, the benefits of more extensive surgery have not been proven in randomized trials. At present, evidence favours the trimodality therapy approach - namely, chemotherapy for three cycles; radical surgery (removal of the parietal pleura, mediastinal pleura pericardium and diaphragm en bloc with the lung inside this envelope); and radical (ideally intensity-modulated) radiotherapy. Comparison of the results with historical controls or a reference population is completely invalid. We have studied the survival in two contemporary series histologically diagnosed between date and date and then given best supportive care (Figure 2). ${ }^{22}$ The Kaplan-Meier survival plots are widely different - far greater than any difference claimed in trials of therapy. We can speculate about whether this is leadtime bias or a difference in diagnostic threshold. What we can be sure of is that, if the upper data were chosen as the comparison group, all treatments would appear disastrous, while if the lower line were chosen, some treatments might look good in comparison. There is no basis on which to choose one over the other for a reference population.

The trimodality treatment plan set out above is so demanding, and must be administered so selectively, that it cannot possibly be evaluated other than within a randomized controlled trial against the best alternative active treatment. The analysis must be by intention to treat: failure to complete treatment is a finding, not a reason to exclude that patient's outcome, otherwise we simply get reports that those who have completed treatment do better than those who do not; ${ }^{23}$ a version of the Will Rogers phenomenon. ${ }^{24}$

\section{FOR AS LONG AS THERE ARE PATIENTS WE CANNOT CURE WHAT CAN WE DO?}

By the time they are diagnosed, many patients with mesothelioma are in such an advanced stage of the disease that most treatment options seem futile. With the

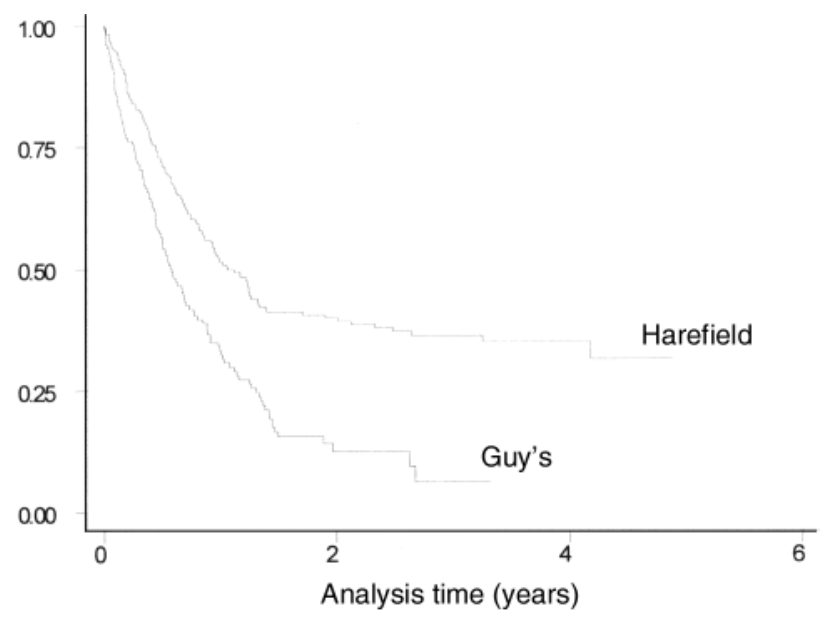

Figure 2 Kaplan-Meier survival graph for mesothelioma patients at two tertiary hospitals in the UK (Ref. 22) 
impending epidemic and the thus far poor results of treatment the question of screening has arisen. Should we screen? Until recently no reliable tumour marker for mesothelioma has been identified, but a serum marker, mesothelin is now under evaluation. ${ }^{25}$ It rises in proportion to the bulk of the disease, so is more likely to pick up already bulky disease rather than be of value in detecting early disease. A negative test offers little or no reassurance. It is no indicator that mesothelioma will not present in years to come. Until we have treatments that we can be sure make a difference it does not appear to us to be in patients' best interests to go looking for disease. We prefer a policy of making the diagnosis as soon as possible after presentation and then doing promptly and effectively the things that we can do. These are:

- Palliate breathlessness by pleurodesis if appropriate

- Consider debulking or radical surgery within a trial

- Consider chemotherapy, preferably within a trial

- Whatever other treatments are considered, make an active plan for symptom control

- Direct patients towards expert legal and compensation advice.

\section{REFERENCES}

1 Health and Safety Executive. Mesothelioma. [www.hse.gov.uk/statistics/ causdis/meso.htm]

2 Toms JR, ed. CancerStats Monograph 2004. London: Cancer Research UK, 2004

3 Hodgson JT, McElvenny DM, Darnton AJ, Price MJ, Peto J. The expected burden of mesothelioma mortality in Great Britain from 2002 to 2050. Br J Cancer 2005;92:587-93

4 Peto J, Decarli A, La Vecchia C, Levi F, Negri E. The European mesothelioma epidemic. Br J Cancer 1999;79:666-72

5 Peto J, Hodgson JT, Matthews FE, Jones JR. Continuing increase in mesothelioma mortality in Britain. Lancet 1995;345:535-9

6 [www.legislation.hmso.gov.uk] 2005

7 LaDou J, Landrigan P, Bailar JC, III, Foa V, Frank A. A call for an international ban on asbestos. Can Med Assoc J 2001;164:489-90

8 Guidotti TL. The debate on banning asbestos. Can Med Assoc J 2001;165:1189-90

9 Butchart EG, Ashcroft T, Barnsley WC, Holden MP. Pleuropneumonectomy in the management of diffuse malignant mesothelioma of the pleura. Experience with 29 patients. Thorax $1976 ; 31: 15-24$
10 Treasure T, Sedrakyan A. Pleural mesothelioma: little evidence, still time to do trials. Lancet 2004;364:1183-5

11 Weder W, Kestenholz P, Taverna C, et al. Neoadjuvant chemotherapy followed by extrapleural pneumonectomy in malignant pleural mesothelioma. J Clin Oncol 2004;22:3451-7

12 Ryan CW, Herndon J, Vogelzang NJ. A review of chemotherapy trials for malignant mesothelioma. Chest 1998;113(1 suppl): $66 \mathrm{~S}-73 \mathrm{~S}$

13 Berghmans T, Paesmans M, Lalami $\mathrm{Y}$, et al. Activity of chemotherapy and immunotherapy on malignant mesothelioma: a systematic review of the literature with meta-analysis. Lung Cancer 2002;38:111-21

14 Vogelzang NJ, Rusthoven JJ, Symanowski J, et al. Phase III study of pemetrexed in combination with cisplatin versus cisplatin alone in patients with malignant pleural mesothelioma. $J$ Clin Oncol $2003 ; 21: 2636-44$

15 Armato SG, III, Oxnard GR, MacMahon H, et al. Measurement of mesothelioma on thoracic CT scans: a comparison of manual and computer-assisted techniques. Med Phys 2004;31:1105-15

16 Boutin C, Rey F, Viallat JR. Prevention of malignant seeding after invasive diagnostic procedures in patients with pleural mesothelioma. A randomized trial of local radiotherapy. Chest 1995;108:754-8

17 Graaf-Strukowska L, van der ZJ, van Putten W, Senan S. Factors influencing the outcome of radiotherapy in malignant mesothelioma of the pleura - a single-institution experience with 189 patients. Int $J$ Radiat Oncol Biol Phys 1999;43:511-16

18 Rusch VW, Rosenzweig K, Venkatraman E, et al. A phase II trial of surgical resection and adjuvant high-dose hemithoracic radiation for malignant pleural mesothelioma. J Thorac Cardiovasc Surg 2001;122:788-95

19 Forster KM, Smythe WR, Starkschall G et al. Intensity-modulated radiotherapy following extrapleural pneumonectomy for the treatment of malignant mesothelioma: clinical implementation. Int $J$ Radiat Oncol Biol Phys 2003;55:606-16

20 Soysal O, Karaoglanoglu N, Demiracan S, et al. Pleurectomy/ decortication for palliation in malignant pleural mesothelioma: results of surgery. Eur J Cardiothorac Surg 1997;11:210-13

21 Sugarbaker DJ, Flores RM, Jaklitsch MT, et al. Resection margins, extrapleural nodal status, and cell type determine postoperative longterm survival in trimodality therapy of malignant pleural mesothelioma: results in 183 patients. J Thorac Cardiovasc Surg 1999;117:54-63

22 Tan C, Swift S, Gilham C, Shaefi S, et al. Survival in surgically diagnosed patients with malignant mesothelioma in current practice. Thorax 2002;57:iii36

23 Aziz T, Jilaihawi A, Prakash D. The management of malignant pleural mesothelioma; single centre experience in 10 years. Eur J Cardiothorac Surg 2002;22:298-305

24 Stephens R. The dangers of subgroup analysis. Lancet Oncol 2001; 2:9

25 Robinson BW, Creaney J, Lake R, et al. Mesothelin-family proteins and diagnosis of mesothelioma. Lancet 2003;362:1612-16 